\title{
Sea Buckthorn (Hippophaë rhamnoides L.) Oil Improves Atopic Dermatitis-Like Skin Lesions via Inhibition of NF-KB and STAT1 Activation
}

\author{
Dian-Dong Hou ${ }^{\mathrm{a}, \mathrm{b}}$ Zheng-Hong $\mathrm{Di}^{\mathrm{c}}$ Rui-Qun $\mathrm{Qj}^{\mathrm{a}}$ He-Xiao Wang ${ }^{\mathrm{a}}$ \\ Song Zheng ${ }^{a}$ Yu-Xiao Hong ${ }^{a}$ Hao Guo $^{a}$ Hong-Duo Chen $^{a}$ Xing-Hua Gao ${ }^{a}$ \\ a Department of Dermatology, The First Hospital of China Medical University, and Key Laboratory of Dermatology, \\ Ministry of Education and Public Health, ${ }^{\mathrm{b}}$ Liaoning University of Traditional Chinese Medicine, and ${ }^{\mathrm{C}}$ Department of \\ Dermatology, Shengjing Hospital of China Medical University, Shenyang, China
}

\section{Keywords}

Sea buckthorn oil · Atopic dermatitis · DNCB .

Hippophaë rhamnoides L. · NF-KB · STAT1

\begin{abstract}
Background and Objectives: The objective of this study was to evaluate the topical effects of sea buckthorn (SBT) oil on atopic dermatitis (AD)-like lesions in a mouse model generated by repeated topical administration of DNCB in BALB/C mice. Methods: DNCB was applied repeatedly on the dorsal skin of mice to induce AD-like lesions. Following AD induction, SBT oil was applied daily on the dorsal skin for 4 weeks. The severity of skin lesions was examined macroscopically and histologically. We further measured the production of MDC/CCL22 and TARC/CCL17 in IFN- $/$ TNF-a activated HaCaT cells. Results: Topically applied SBT oil in DNCB-treated mice ameliorated the severity score of dermatitis, decreased epidermal thickness, reduced spleen and lymph node weights, and prevented mast cell infiltration. In addition, SBT oil suppressed the Th2 chemokines TARC and MDC
\end{abstract}

\section{KARGER}

(C) 2017 S. Karger AG, Basel

E-Mail karger@karger.com

www.karger.com/spp via dose-dependent inhibition of NF-KB, JAK2/STAT1, and p38-MAPK signaling pathways in IFN- $\gamma /$ TNF- $a$-activated $\mathrm{HaCaT}$ cells. Conclusion: These results suggest that SBT oil had a beneficial effect on AD-like skin lesions, partially via inhibition of the Th2 chemokines TARC and MDC in inflamed skin.

(c) 2017 S. Karger AG, Basel

\section{Introduction}

Atopic dermatitis (AD) is a chronic inflammatory skin disease accompanied by an itchy and scaly rash. As a serious global public health problem [1], the morbidity of $\mathrm{AD}$ has increased in recent years [2]. $\mathrm{AD}$ is a disease arising from complex interaction of genetic factors with skin barrier dysfunction and environmental factors $[3,4]$. $\mathrm{AD}$ is associated with $\mathrm{Th} 2$ cell-mediated allergic reactions characterized by increased production of Th2 cytokines in skin lesions, mast cell activation, and aberrant IgE production $[5,6]$.
Xing-Hua Gao, MD, PhD

Department of Dermatology, The First Hospital of China Medical University 155 N. Nanjing Street

Shenyang 110001 (China)

E-Mail gaobarry@ hotmail.com 
Table 1. Major fatty acids and contents of sitosterol and $\beta$-carotene in sea buckthorn oil

\begin{tabular}{|c|c|c|c|c|c|c|c|c|}
\hline \multicolumn{7}{|l|}{ Fatty acids, \% } & \multirow{2}{*}{$\begin{array}{l}\text { Sitosterol, } \\
\mathrm{mg} / \mathrm{g}\end{array}$} & \multirow{2}{*}{$\begin{array}{l}\beta \text {-Carotene, } \\
\mathrm{mg} / \mathrm{g}\end{array}$} \\
\hline $\begin{array}{l}\text { myristic } \\
\text { acid (C14:0) }\end{array}$ & $\begin{array}{l}\text { palmitic } \\
\text { acid }(\mathrm{C} 16: 0)\end{array}$ & $\begin{array}{l}\text { palmitoleic } \\
\text { acid }(\mathrm{C} 16: 1)\end{array}$ & $\begin{array}{l}\text { stearic } \\
\text { acid (C18:0) }\end{array}$ & $\begin{array}{l}\text { oleic } \\
\text { acid (C18:1) }\end{array}$ & $\begin{array}{l}\text { linoleic } \\
\text { acid (C18:2) }\end{array}$ & $\begin{array}{l}\text { linolenic } \\
\text { acid (C18:3) }\end{array}$ & & \\
\hline 0.83 & 26.87 & 27.52 & 1.2 & 33.1 & 4.3 & 1.5 & 15.0 & 6.9 \\
\hline
\end{tabular}

Therapies for AD mainly include systemic anti-histamines, topical steroids, and immunosuppressive agents [7]. As most of these treatment methods are associated with the rebound phenomenon, side effects, or intermittent recurrences $[8,9]$, many patients are still worried about adverse effects of long-term treatment with these agents [10]. Presently, there is global interest in seeking new anti-inflammatory agents from natural materials $[11,12]$.

Sea buckthorn (SBT) (Hippophaë rhamnoides L.) is a wild shrub belonging to the Elaeagnaceae family. Berries of SBT have been used in the Chinese, Mongolian, and Tibetan traditional medicine for the treatment of various diseases for more than 1,000 years [13]. Many researchers have paid much attention to SBT for its various medicinal values, such as anti-inflammatory and immunoregulatory effects [14-16]. All parts of SBT are rich sources of bioactive agents [9]. SBT berry oil is a kind of multifunctional natural oil and contains abundant bioactive substances such as $\omega-3$ and $\omega-6$ fatty acids, tocopherols, phytosterols, and carotenoids [17].

This study estimated the topical effects of SBT oil on $\mathrm{AD}$ mouse models induced by 2,4-dinitrochlorobenzene (DNCB). It was observed that topical application of SBT oil reduced the severity of dermatitis, infiltration of mast cells, epidermal thickness, and spleen and lymph node weights. Furthermore, there was an inhibitory effect of SBT oil on TARC and MDC expression in IFN- $\gamma /$ TNF- $\alpha-$ treated $\mathrm{HaCaT}$ keratinocytes.

\section{Materials and Methods}

\section{SBT Oil}

SBT oil was purchased from Dongning Pharmceutical Co., Ltd. The oil was extracted from dried SBT residues (including seeds, berry flesh, and peel), using an aseptic supercritical carbon dioxide process. An HP-5MS capillary column $(30 \mathrm{~m} \times 0.25 \mathrm{~mm}, 0.25 \mu \mathrm{m}$; Agilent Technologies Inc., Santa Clara, CA, USA) in a GC/MS (5975C, Agilent Technologies Inc.) was adopted for the analysis of samples. Samples were injected into the column and run using the split mode (split ratio $=10: 1$ ). The helium carrier gas was programmed to maintain a constant flow rate of $1 \mathrm{~mL} / \mathrm{min}$. Oven heating was initially $80^{\circ} \mathrm{C}$ for $3 \mathrm{~min}$ and then finally raised to $300^{\circ} \mathrm{C}$ at $4^{\circ} \mathrm{C} / \mathrm{min}$. Fatty acids were identified by a reference standard mixture FAME (Supelco, Bellefonte, PA, USA) analyzed under the same operating conditions as those employed for FAME of the samples. The SBT oil components are exhibited in Table 1.

\section{Animals}

Female BALB/c mice, aged 6 weeks, were adopted in this study. The mice were provided by Liaoning Changsheng Biotechnology Co., Ltd (Benxi, China). All mice were housed under pathogenfree conditions and allowed free access to water and food. All experimental procedures were in accordance with the guidelines approved by the Ethical Committee of Experimental Animal Care at the China Medical University (Shenyang, China).

\section{Animal Treatment}

Mice were divided into 5 groups: the normal control group (a), DNCB group (b), and groups treated with DNCB plus topical dexamethasone acetate (DEX) (c), DNCB plus topical olive oil (d), and DNCB plus topical SBT oil (e). Each group comprised 6 mice.

To induce AD-like skin lesions, DNCB (Sigma-Aldrich, St. Louis, MO, USA) was applied onto the dorsal skin [18]. An area of approximately $6 \mathrm{~cm}^{2}$ was shaved on each mouse back using an electric clipper 1 day before DNCB sensitization. As shown in Figure 1, for sensitization, $200 \mu$ of $1 \%$ DNCB solution (dissolved in acetone) was applied for 4 times from day 1 to day 11 . To induce AD-like lesions, $200 \mu \mathrm{l}$ of $0.5 \%$ DNCB solution was applied on the dorsal skin once every 3 days from day 15 to day 42 . The SBT oil $(40 \mu \mathrm{L})$ was prepared in cream form dosed at $200 \mu \mathrm{L}$ for each treatment. The cream was applied to the dorsal skin once a day from day 15 to day 42 . Olive oil was provided by Sinopharm Chemical Reagent Co., Ltd, Shanghai, China. DEX (1 mg/kg) cream was purchased from Hubei Ketian Pharmaceutical Co., Ltd, Hubei, China. Mice were sacrificed by $\mathrm{CO}_{2}$ inhalation, and samples were collected. Spleen and axillary lymph nodes were removed and weighed.

\section{Evaluation of AD Severity}

Dermatitis severity was assessed according to 4 specific parameters once a week: (1) hemorrhage/erythema, (2) dryness/crusting, (3) erosion/excoriation, and (4) edema [19]. Each component was scored on a scale from 0 (none), 1 (mild), 2 (moderate), to 3 (severe); the sum of the individual scores was defined as the overall dermatitis score.

\section{Histopathological Studies}

The dorsal skin of mice was collected on the final day of the schedule, fixed in $10 \%$ formalin, and embedded in paraffin. Skin sections ( $5 \mu \mathrm{m}$ thick) were cut and stained with either H\&E stain- 
Fig. 1. Schematic diagram of the experimental protocol. SBT, sea buckthorn.
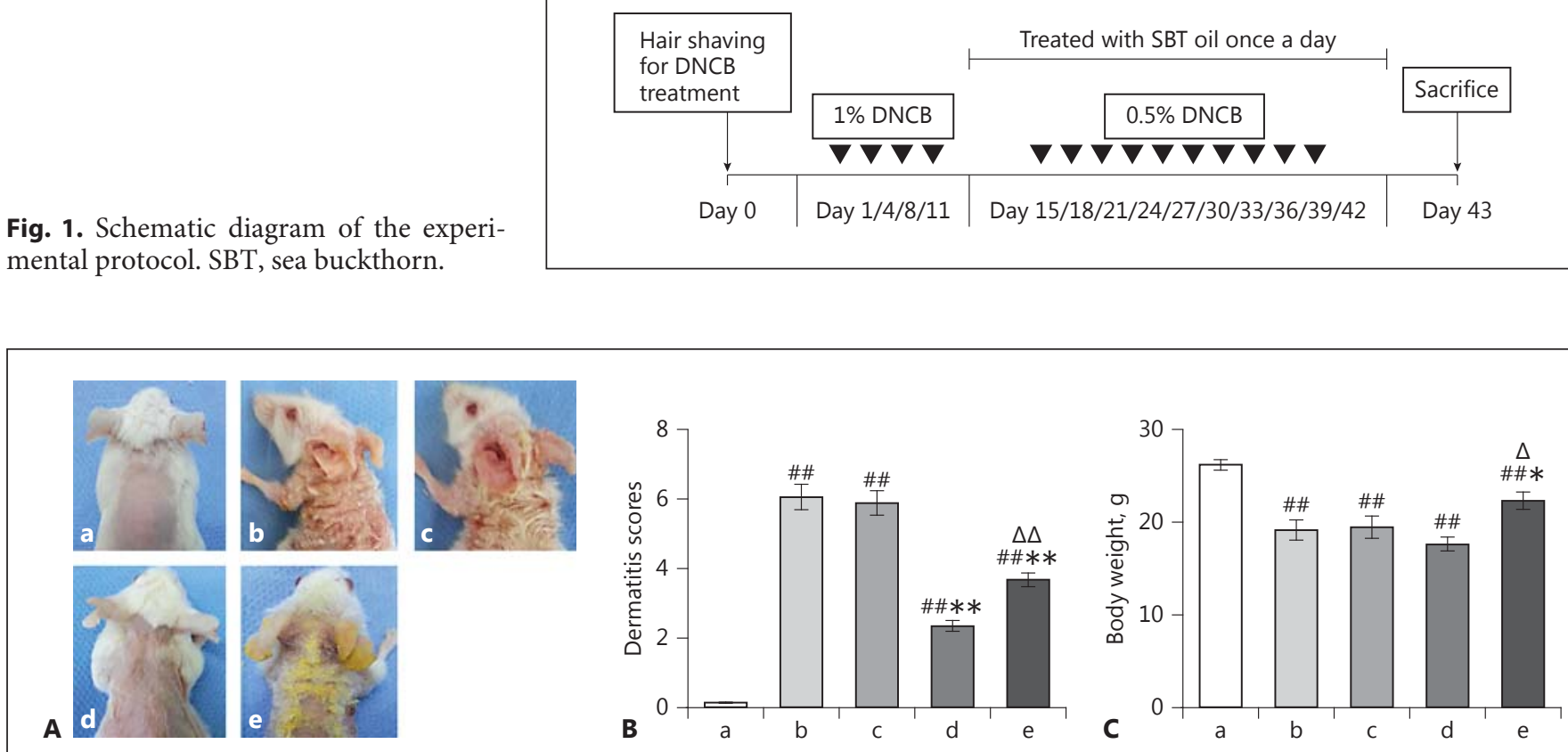

Fig. 2. Effects of sea buckthorn (SBT) oil on DNCB-induced atopic dermatitis (AD)-like skin lesions and body weight of mice. A Example of the clinical severity of $\mathrm{AD}$-like skin lesions in the normal control group (a); DNCB group (b); DNCB plus olive oil treatment group (c); DNCB plus dexamethasone (DEX) acetate treatment group (d); and DNCB plus SBT oil treatment group (e). B The dermatitis scores were defined as the sum of scores based on the various $\mathrm{AD}$ symptoms. C The body weight of the mice. ${ }^{\# \#} p<$ 0.01 vs. the control group; ${ }^{* *} p<0.01,{ }^{*} p<0.05$ vs. the DNCB group; ${ }^{\Delta \Delta} p<0.01,{ }^{\Delta} p<0.05$ vs. the DNCB + DEX group. ing for counting of inflammatory cell numbers or with toluidine blue staining for counting mast cells.

\section{Cell Culture}

Human keratinocyte HaCaT cells were cultured in Dulbecco's modified Eagle's medium (DMEM, high glucose), which was supplemented with $10 \%$ fetal bovine serum (FBS), penicillin (100 U/ $\mathrm{mL})$, and streptomycin $(100 \mu \mathrm{g} / \mathrm{mL})$ at $37^{\circ} \mathrm{C}$ in a humidified $5 \%$ $\mathrm{CO}_{2}$ incubator. FBS, DMEM, PBS ( $\mathrm{pH} 7.4$ ), penicillin, and streptomycin were all provided by Hyclone Co. (USA).

\section{TARC/CCL17 and MDC/CCL22 Production}

HaCaT cells $\left(1.0 \times 10^{6}\right.$ cells/well $)$ were seeded in 6-well plates. After $24 \mathrm{~h}$, the cells were washed and treated with SBT oil in $1 \mathrm{~mL}$ serum-free media containing IFN- $\gamma(10 \mathrm{ng} / \mathrm{mL}) / \mathrm{TNF}-\alpha(10 \mathrm{ng} /$ $\mathrm{mL}$ ) (R\&D Systems, Minneapolis, MN, USA) for $24 \mathrm{~h}$. The culture medium of the cells was harvested, and the production of TARC and MDC were determined using an ELISA kit (Cusabio, Wuhan, China).

\section{Western Blots}

Total protein was extracted from HaCaT cells using RIPA lysis buffer (Beyotime Biotechnology, Nantong, China) according to the manufacturer's protocol. The protein concentrations were determined using the Bradford protein assay (Bio-Rad, Hercules, CA, USA). Proteins were electrophoresed on $10 \%$ SDS polyacryl- amide gel and transferred to a nitrocellulose membrane by electroblotting. The membrane was incubated with primary antibod-

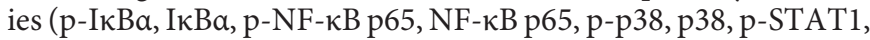
STAT1, p-JAK2, JAK2, and $\beta$-actin) at $4^{\circ} \mathrm{C}$ overnight followed by incubation with the appropriate HRP-conjugated secondary antibodies (Proteintech, Wuhan, China) for $1 \mathrm{~h}$ at room temperature. All primary antibodies were provided by Ruiying Biological Technology Co., Ltd, Suzhou, China. The membranes were visualized by the ECL detection system (Bio-Rad Laboratories).

\section{Statistical Analysis}

Results are presented as means \pm SD. The significance of differences of all results was analyzed by one-way analysis of variance (ANOVA) followed by the Dunnett $t$ test. $\mathrm{p}<0.05$ was considered significant.

\section{Results}

\section{SBT Oil Suppressed the Development of}

\section{DNCB-Induced AD-Like Mouse Skin Lesions}

To evaluate the effect of SBT oil against AD-like skin lesions, $1 \mathrm{~mL} / \mathrm{kg}$ SBT oil was applied on mice once a day along with induction of $\mathrm{AD}$-like skin lesions by $\mathrm{DNCB}$ 

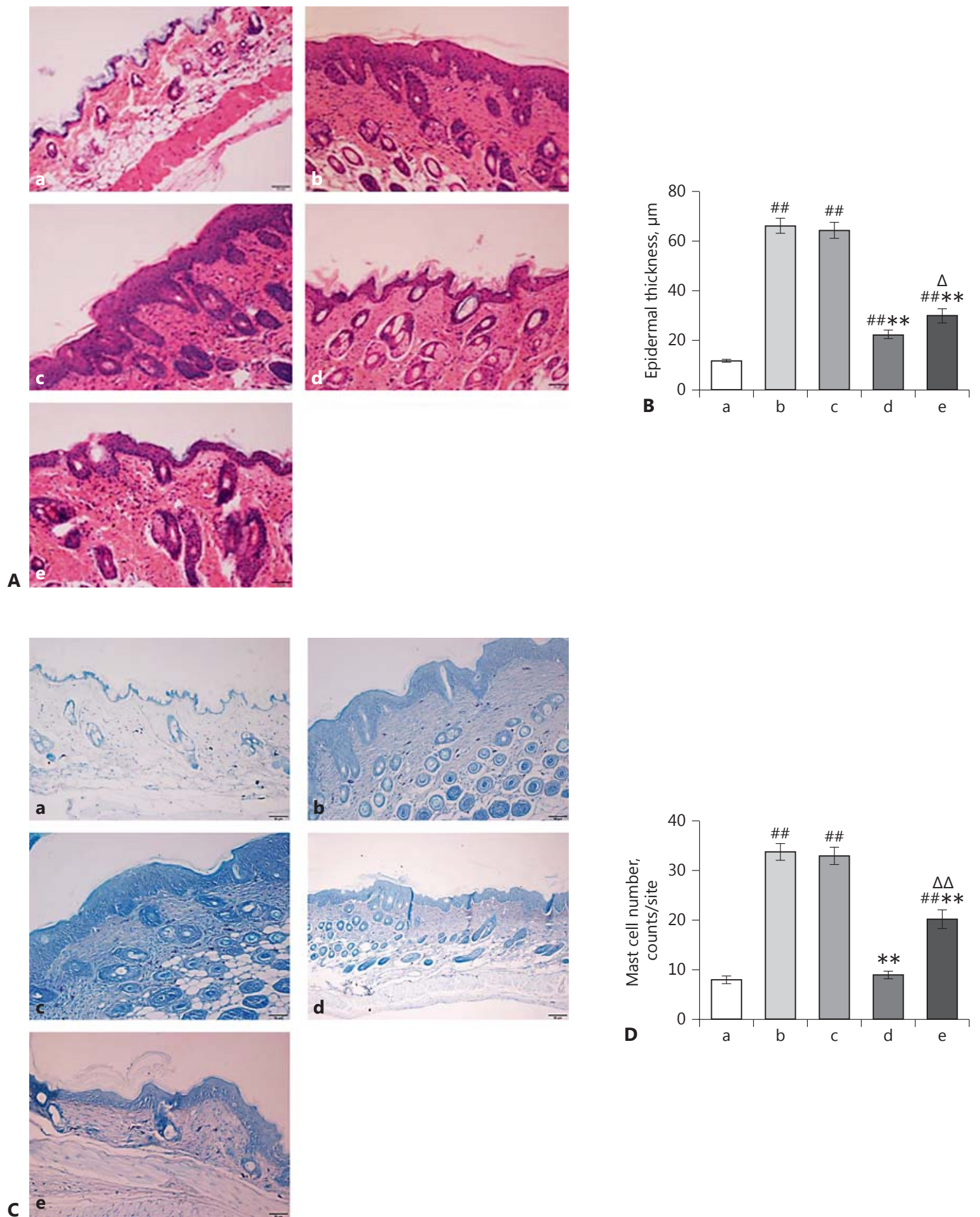

Fig. 3. Effects of sea buckthorn (SBT) oil on histological dorsal skin lesions in the normal control group (a); DNCB group (b); DNCB plus olive oil treatment group (c); DNCB plus dexamethasone (DEX) acetate treatment group (d); and DNCB plus SBT oil treatment group (e). A H\&E. $\times 200$. B Epidermal thickness was ana-

lyzed in H\&E-stained tissue. C Toluidine blue. $\times 200$. D The number of mast cells was analyzed in the toluidine blue-stained sections. ${ }^{\# \#} p<0.01$ vs. the control group; ${ }^{* *} p<0.01$ vs. the DNCB group; ${ }^{\Delta} p<0.05,{ }^{\Delta \Delta} p<0.01$ vs. the DNCB + DEX group. 


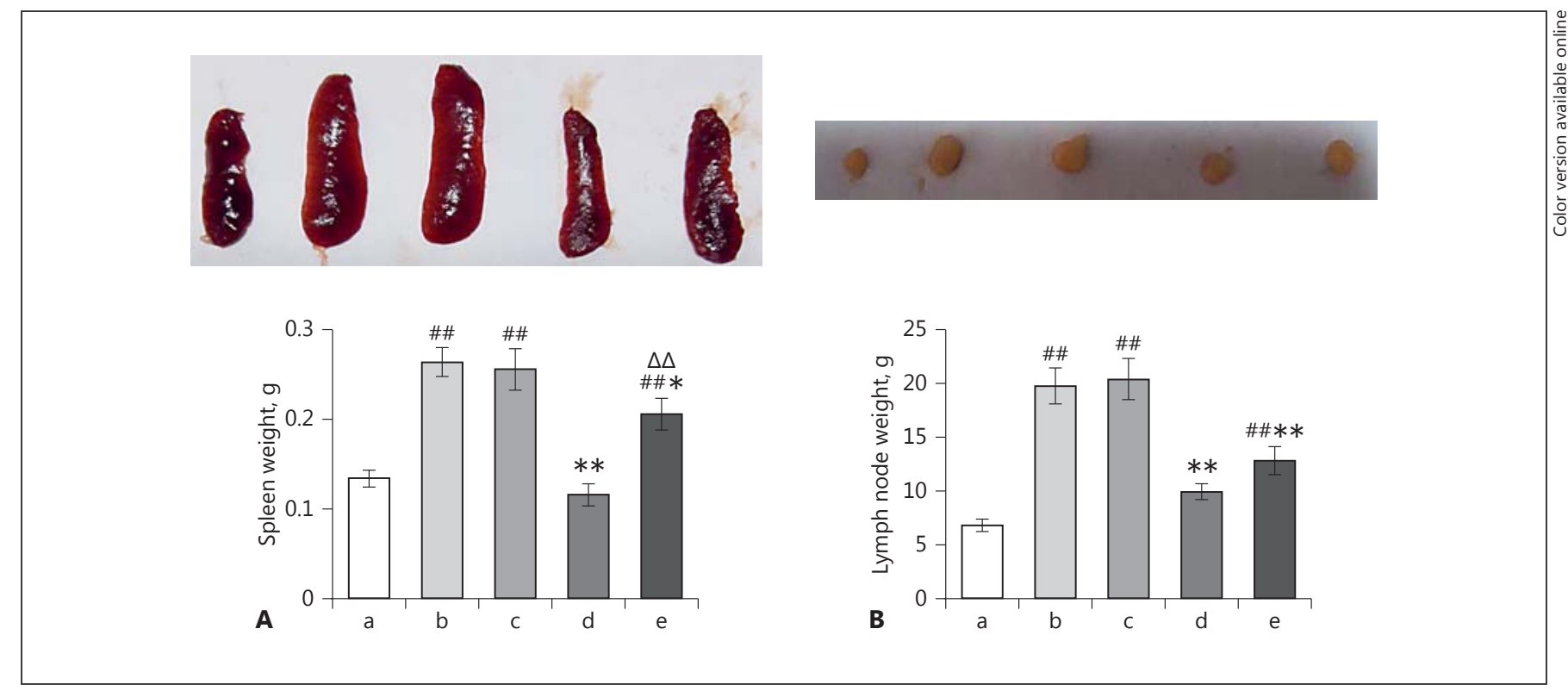

Fig. 4. Effect of sea buckthorn (SBT) oil on spleen and lymph node weights in DNCB-induced atopic dermatitis-like skin. Spleen (A) and lymph node weights (B) in the normal control group (a); DNCB group (b); DNCB plus olive oil treatment group (c); DNCB plus dexamethasone (DEX) acetate treatment group (d); and DNCB plus SBT oil treatment group (e). ${ }^{\# \#} p<0.01$ vs. the control group; ${ }^{* *} p<0.01,{ }^{*} p<0.05$ vs. the DNCB group; ${ }^{\Delta \Delta} p<0.01$ vs. the DNCB + DEX group. administration. The severity of dermatitis was evaluated once a week. The DNCB-induced AD-like skin lesions resulted in severe itching, mild erythema, and hemorrhage, which was followed by abnormal keratinization, dryness, excoriation, and edema of the skin. After SBT oil or DEX application for 4 weeks, SBT oil significantly decreased DNCB-induced AD severity; the dermatitis scores of the DEX group decreased more markedly than that of SBT oil group (Fig. 2A, B). However, more body weight reduction was observed in the DEX group than in the SBT oil group (Fig. 2C). Compared to the DNCB group, olive oil had no protective effect against $\mathrm{AD}$-like skin lesions in mice.

\section{Histologically, SBT Oil Improved the Skin and}

Decreased Mast Cell Infiltration in Mice

To evaluate whether SBT oil reduces infiltration of inflammatory cells into AD skin lesions, $\mathrm{H} \& \mathrm{E}$ staining was performed on the skin sections. Repetitive DNCB treatments induced epidermal hyperplasia and increased epidermal thickness. In contrast, SBT oil application suppressed epidermal hyperplasia and epidermal thickness induced by DNCB (Fig. 3A, B). Toluidine blue staining was also performed to trace mast cells. Repetitive DNCB treatments increased mast cell numbers in the skin sec- tions. However, this feature was inhibited by SBT oil compared with the DNCB group (Fig. 3C, D). The effects of SBT oil on DNCB-induced epidermal hyperplasia and mast cell infiltration were also studied.

\section{SBT Oil Decreased the Spleen and Lymph Node} Weights in Mice with AD-Like Skin Lesions Induced by DNCB

To determine whether SBT oil decreases spleen and lymph node weights, we weighed the spleen and axillary lymph nodes. Results demonstrated an increase in both spleen and lymph node weights in DNCB-treated mice, which were both decreased by SBT oil application (Fig. 4).

\section{SBT Oil Inhibited IFN- $\gamma / T N F-\alpha-I n d u c e d$ Production of TARC and MDC in HaCaT Cells}

In order to determine whether SBT oil suppresses TARC and MDC production, HaCaT cells were co-treated with IFN- $\gamma$ and TNF- $\alpha$ in the presence or absence of SBT oil for $24 \mathrm{~h}$, and culture supernatants were harvested for chemokine detection with ELISA. TARC and MDC production in $\mathrm{HaCaT}$ cells increased significantly following stimulation with IFN- $\gamma / T N F-\alpha$. Increased TARC and MDC production was suppressed by SBT oil in a dosedependent manner (Fig. 5). The results suggest that SBT 


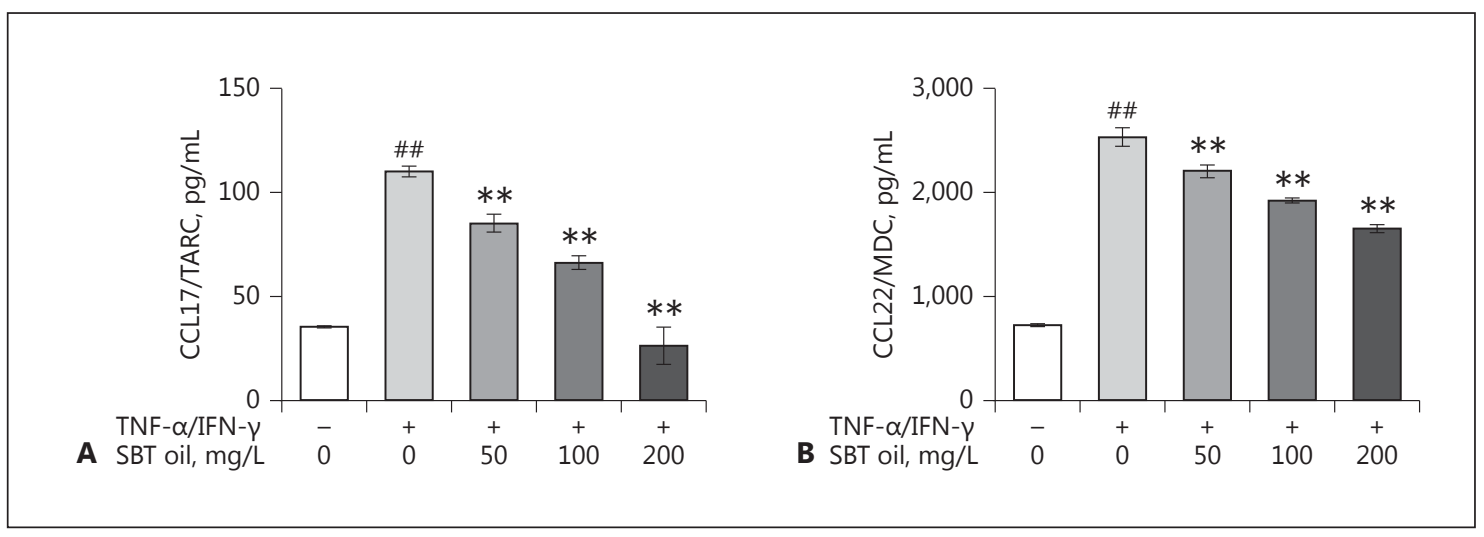

Fig. 5. Effects of sea buckthorn (SBT) oil on IFN- $\gamma /$ TNF- $\alpha$-induced TARC (A) and MDC levels (B) in HaCaT cells. ${ }^{\# \#} p<0.01$ vs. the control group; ${ }^{* *} p<0.01$ vs. the TNF- $\alpha / \mathrm{IFN}-\gamma$-treated group.

oil can inhibit the expression of Th2 chemokines such as TARC and MDC in IFN- $\gamma /$ TNF- $\alpha$-stimulated HaCaT cells.

SBT Oil Inhibited IFN- $\gamma / T N F-\alpha-I n d u c e d ~ N F-\kappa B$, JAK/ STAT1, p38-MAPK Activation in $\mathrm{HaCaT}$ Cells

In order to determine whether SBT oil has an influence on the activation of the NF- $\kappa \mathrm{B}$, JAK2/STAT1, and p38MAPK signaling pathways in IFN- $\gamma /$ TNF- $\alpha$-stimulated $\mathrm{HaCaT}$ cells, $\mathrm{HaCaT}$ cells were co-treated with IFN- $\gamma$ and TNF- $\alpha$ in the presence or absence of SBT oil for $24 \mathrm{~h}$. Total proteins extracted from cells were assessed in terms of NF- $\kappa B$, JAK2-STAT1, and p38-MAPK activation by immunoblotting. As shown in Figure 6, SBT oil inhibited IFN- $\gamma /$ TNF- $\alpha$-induced phosphorylation of I $\kappa \mathrm{B} \alpha, \mathrm{NF}-\kappa \mathrm{B}$ p65, JAK2, STAT1, and p38 expression in a dose-dependent manner. These results suggest that suppression of IFN- $\gamma /$ TNF- $\alpha$-induced TARC and MDC production by SBT oil is probably mediated by the inhibition of NF- $\kappa \mathrm{B}$, JAK/STAT1, and p38-MAPK activation.

\section{Discussion}

In this study, we demonstrated the inhibitory effects and molecular mechanisms of SBT oil on AD-like skin symptoms both in vivo and in vitro.

$\mathrm{AD}$ is associated with immune system dysregulation, genetic and psychological factors, epidermal barrier defects, and environmental factors [20]. The current standard treatment for severe AD has long consisted of topical steroid (corticosteroids) application or administration of immunosuppressive agents, but these treatments

Sea Buckthorn Oil for Atopic Dermatitis may be associated with potentially serious adverse effects [21]. It is necessary to develop new and effective treatments for patients suffering from $\mathrm{AD}$. Traditional herbal extracts have been widely used in the treatment of inflammatory diseases as a folk remedy in Asia [8].

SBT has been ascribed a wide variety of pharmacological effects such as cytoprotective, anti-inflammatory, and immunomodulatory activity [22]. Topical application of SBT oil improved burns, healing of wounds, and irradiation dermatitis [23]. Based on the anti-inflammatory effects and its application in skin diseases, we examined the effects of SBT oil in AD-like skin lesions in vivo and in vitro.

In mice, skin and immunological alterations in DNCBinduced dermatitis were similar to those observed in human $\mathrm{AD}$ [24-26], including clinical features such as skin erosion, hemorrhage, edema, and increased serum IgE levels [27]. Therefore, the DNCB-induced BALB/c mice model was adopted to evaluate the effects of SBT oil on $\mathrm{AD}$ in vivo.

The symptoms observed in the mice studied here are consistent with those observed in the DNCB-induced model of AD-like lesions, such as edema, erythema/ hemorrhage, scaling/dryness, and excoriation/erosion. In this model, SBT oil remarkably suppressed the development of AD-like skin lesions in mice after treatment for 4 weeks. The effect of SBT oil on AD-like lesions was lower than with DEX, but a higher body weight reduction was observed in the DEX group than the SBT oil group, which indicated that DEX had more side effects than SBT oil.

The thickness of the epidermis was significantly reduced following application of SBT oil compared with the

Skin Pharmacol Physiol 2017;30:268-276 273 


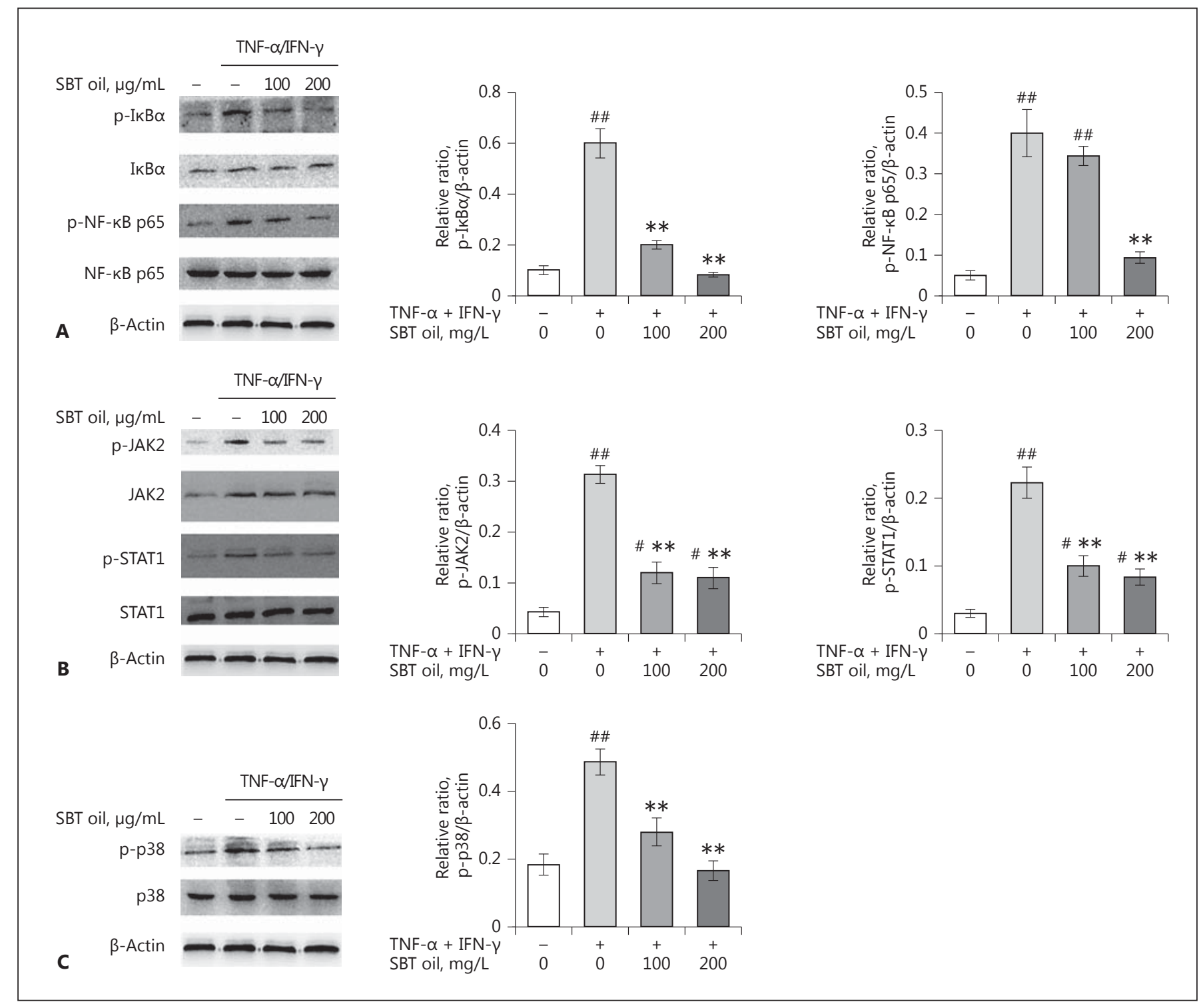

Fig. 6. Effects of sea buckthorn (SBT) oil on TNF- $\alpha / \mathrm{IFN}-\gamma$-induced NF- $\kappa$ B, JAK2/STAT1, p38-MAPK activation in HaCaT cells. Total protein extracted from cells treated with IFN- $\gamma /$ TNF- $\alpha$ were analyzed for the expression of signaling molecules NF- $\mathrm{B}(\mathbf{A}), \mathrm{JAK} 2 /$
STAT1 (B), and p38-MAPK by Western blot analysis (C). $\beta$-Actin was adopted to confirm an equal protein loading. ${ }^{\# \#} \mathrm{p}<0.01,{ }^{\#} \mathrm{p}<$ 0.01 vs. the control group; ${ }^{* *} p<0.01$ vs. the TNF- $\alpha /$ IFN- $\gamma$-treated group.
DNCB group, demonstrating that SBT oil could inhibit lichenification and protect the skin barrier function $[28$, 29].

Infiltration of mast cells is one of the main features of AD lesions. Mast cells can release inflammatory mediators to mediate inflammatory responses such as allergic reactions $[30,31]$. Histologically, there was a high degree of mast cell and inflammatory cell infiltration in the skin tissue of DNCB-sensitized mice, and SBT oil decreased the infiltration of mast cells and inflammatory cells in the skin.

The weights of the spleen and local lymph nodes increased after topical application of allergen [32, 33]. Local lymph node and spleen weights were both markedly increased in DNCB-induced mice, which were significantly reduced following application of SBT oil.

Compared to the DNCB group, olive oil had no protective effect against $\mathrm{AD}$-like skin lesions in mice. There 
was a report that topical treatment with olive oil significantly damaged the skin barrier, and researchers considered that olive oil has the potential to promote the development of, and exacerbate existing, $\mathrm{AD}$. The use of olive oil for the treatment of dry skin and infant massage should, therefore, be discouraged [34].There are great differences in ingredients between olive oil and SBT oil. Besides oleic acid, SBT pulp oil has an obviously higher palmitoleic acid content than olive oil [35]. Palmitoleic acid shows anti-inflammatory ability via reducing proinflammatory cytokines $[35,36]$. The SBT fruit is a rich source of flavonoids ( $0.2 \%$ in juice and $0.6 \%$ in dry fruits). SBT flavonoids also have anti-inflammatory and immunomodulatory activity [37].

This study confirmed the inhibitory effects of SBT oil on the expression of TARC and MDC in IFN- $\gamma /$ TNF- $\alpha-$ treated $\mathrm{HaCaT}$ cells, an in vitro model of $\mathrm{AD}$ [38]. CCR4 is a predominant chemokine receptor on Th2 cells [39]. TARC and MDC are both ligands of CCR4, which can attract inflammatory lymphocytes to the skin [12]. Thus, TARC and MDC are both critical in the pathogenesis of $\mathrm{AD}$, and inhibiting TARC and MDC expression in skin keratinocytes may improve $\mathrm{AD}$ symptoms [40]. The results suggested that $\mathrm{SBT}$ oil might improve AD-like symptoms via reduced TARC and MDC production by keratinocytes.

Studies have indicated that the regulation of TARC and MDC expression in $\mathrm{HaCaT}$ cells is related to the NF$\kappa \mathrm{B}$ and JAK/STAT signaling pathways $[38,41]$. Our results showed that IFN- $\gamma$ and TNF- $\alpha$ can activate NF- $\kappa B$ and STAT1 in keratinocytes; however, this feature was significantly suppressed by SBT oil.

STAT1 is activated by ERK, JNK, p38 MAP, and JAK kinases in response to cytokines such as TNF- $\alpha$ and IFN- $\gamma$ [42]. Previous studies showed that p38 MAPK and JAK2, but not ERK and JNK kinases, are involved in the regulation of IFN- $\gamma /$ TNF- $\alpha$-induced TARC and MDC expression in $\mathrm{HaCaT}$ cells $[12,38,43]$. The results indicated that SBT oil suppressed IFN- $\gamma /$ TNF- $\alpha$-induced phosphorylation of p38 and JAK2 in HaCaT cells, which suggested that SBT oil inhibited the production of TARC and MDC in IFN- $\gamma / \mathrm{TNF}-\alpha$-stimulated $\mathrm{HaCaT}$ cells by suppression of JAK2 pathways and p38 MAPK activated by IFN- $\gamma$ and TNF- $\alpha$.

Taken together, our results indicated that SBT oil suppressed TARC and MDC production in IFN- $\gamma /$ TNF- $\alpha-$ stimulated $\mathrm{HaCaT}$ cells by inhibiting activation of the NF- $\mathrm{B}$, JAK2/STAT1, and p38-MAPK signaling pathways.

\section{Conclusion}

In summary, the study indicated that SBT oil had antiinflammatory effects against DNCB-induced atopic symptoms in mice and suppressed the production of Th2-type chemokines TARC and MDC in IFN- $\gamma /$ TNF- $\alpha$ stimulated $\mathrm{HaCaT}$ cells via blockade of NF- $\mathrm{KB} / \mathrm{STAT} 1$ signal pathway activation. It is expected that SBT oil might be a useful therapeutic agent for the treatment of patients with $\mathrm{AD}$.

\section{Acknowledgment}

This project was supported by the China Postdoctoral Science Foundation (2015M571345), the Public Welfare Program, Ministry of Health, China (201202013), and the National Natural Science Foundation of China (81303079).

\section{Statement of Ethics}

All experimental procedures were conducted according to the guidelines provided by the ethical committee of experimental animal care at China Medical University (Shenyang, China).

\section{Disclosure Statement}

The authors state no conflict of interest.

\section{References}

Sea Buckthorn Oil for Atopic Dermatitis
1 Orfali RL, Sato MN, Santos VG, et al: Staphylococcal enterotoxin B induces specific IgG4 and IgE antibody serum levels in atopic dermatitis. Int J Dermatol 2015;54:898-904.

2 Park S, Bae JH: Fermented food intake is associated with a reduced likelihood of atopic dermatitis in an adult population (Korean $\mathrm{Na}$ tional Health and Nutrition Examination Survey 2012-2013). Nutr Res 2016;36:125-133.
3 Cha HS, Kim WJ, Lee MH, et al: Inhibitory effect of Pterocarpus indicus Willd water extract on IgE/Ag-induced mast cell and atopic dermatitis-like mouse models. Biosci Biotechnol Biochem 2016;80:911-919.

4 Grewe M, Bruijnzeel-Koomen CA, Schopf E, et al: A role for Th1 and Th2 cells in the immunopathogenesis of atopic dermatitis. Immunol Today 1998;19:359-361. 
5 Brandt EB, Sivaprasad U: Th2 cytokines and atopic dermatitis. J Clin Cell Immunol 2011; 2:110.

6 Leung DY, Boguniewicz M, Howell MD, Nomura I, Hamid QA: New insights into atopic dermatitis. J Clin Invest 2004;113:651-657.

7 Choi JK, Kim SH: Inhibitory effect of galangin on atopic dermatitis-like skin lesions. Food Chem Toxicol 2014;68:135-141.

8 Choi SE, Park KH, Jeong MS, et al: Effect of Alnus japonica extract on a model of atopic dermatitis in NC/Nga mice. J Ethnopharmacol 2011;136:406-413.

9 Hsu CJ, Wang LF: Emerging treatment of atopic dermatitis. Clin Rev Allergy Immunol 2007;33:199-203.

10 Choi JH, Park BH, Kim HG, et al: Inhibitory effect of Psidium guajava water extract in the development of 2,4-dinitrochlorobenzeneinduced atopic dermatitis in NC/Nga mice. Food Chem Toxicol 2012;50:2923-2929.

11 Choi JH, Jin SW, Han EH, et al: Platycodon grandiflorum root-derived saponins attenuate atopic dermatitis-like skin lesions via suppression of NF- $\mathrm{\kappa B}$ and STAT1 and activation of Nrf2/ARE-mediated heme oxygenase- 1 . Phytomedicine 2014;21:1053-1061.

12 Jung M, Lee TH, Oh HJ, et al: Inhibitory effect of 5,6-dihydroergosteol-glucoside on atopic dermatitis-like skin lesions via suppression of NF- $\kappa B$ and STAT activation. J Dermatol Sci 2015;79:252-261.

13 Yang B, Kalimo KO, Mattila LM, et al: Effects of dietary supplementation with sea buckthorn (Hippophaë rhamnoides) seed and pulp oils on atopic dermatitis. J Nutr Biochem 1999; 10:622-630.

14 Diandong H, Feng G, Zaifu L, Helland T, Weixin F, Liping C: Sea buckthorn (Hippophä̈ rhamnoides L.) oil protects against chronic stress-induced inhibitory function of natural killer cells in rats. Int J Immunopathol Pharmacol 2016;29:76-83.

15 Wang Y, Huang F, Zhao L, et al: Protective effect of total flavones from Hippophaëe rhamnoides L. against visible light-induced retinal degeneration in pigmented rabbits. J Agric Food Chem 2016;64:161-170.

16 Wang Y, Zhao L, Huo Y, et al: Protective effect of proanthocyanidins from sea buckthorn (Hippophae rhamnoides L.) seed against visible light-induced retinal degeneration in vivo. Nutrients 2016;8:245.

17 Basu M, Prasad R, Jayamurthy P, Pal K, Arumughan C, Sawhney RC: Anti-atherogenic effects of seabuckthorn (Hippophaea rhamnoides) seed oil. Phytomedicine 2007;14:770777.
18 Li Y, Chen L, Du Y, Huang D, Han H, Dong $\mathrm{Z}$ : Fluoxetine ameliorates atopic dermatitislike skin lesions in BALB/c mice through reducing psychological stress and inflammatory response. Front Pharmacol 2016;7:318.

19 Choi JH, Jin SW, Park BH, et al: Cultivated ginseng inhibits 2,4-dinitrochlorobenzeneinduced atopic dermatitis-like skin lesions in NC/Nga mice and TNF- $\alpha /$ IFN- $\gamma$-induced TARC activation in HaCaT cells. Food Chem Toxicol 2013;56:195-203.

20 Fonacier LS, Dreskin SC, Leung DY: Allergic skin diseases. J Allergy Clin Immunol 2010; 125:S138-S149.

21 Gelbard CM, Hebert AA: New and emerging trends in the treatment of atopic dermatitis. Patient Prefer Adherence 2008;2:387-392.

22 Suryakumar G, Gupta A: Medicinal and therapeutic potential of sea buckthorn (Hippophae rhamnoides L.). J Ethnopharmacol 2011; 138:268-278.

23 Patel CA, Divakar K, Santani D, Solanki HK, Thakkar JH: Remedial prospective of Hippophae rhamnoides Linn. (sea buckthorn). ISRN Pharmacol 2012;2012:436857.

24 Fujii Y, Takeuchi H, Sakuma S, Sengoku T, Takakura S: Characterization of a 2,4-dinitrochlorobenzene-induced chronic dermatitis model in rats. Skin Pharmacol Physiol 2009; 22:240-247.

25 Jin H, He R, Oyoshi M, Geha RS: Animal models of atopic dermatitis. J Invest Dermatol 2009;129:31-40.

26 Yang G, Lee K, Lee MH, Kim SH, Ham IH, Choi HY: Inhibitory effects of Chelidonium majus extract on atopic dermatitis-like skin lesions in NC/Nga mice. J Ethnopharmacol 2011;138:398-403.

27 Choi YY, Kim MH, Kim JH, et al: Schizonepeta tenuifolia inhibits the development of atopic dermatitis in mice. Phytother Res 2013; 27:1131-1135.

28 Lee J, Choi YY, Kim MH, et al: Topical application of Angelica sinensis improves pruritus and skin inflammation in mice with atopic dermatitis-like symptoms. J Med Food 2016; 19:98-105.

29 Proksch E, Jensen JM, Elias PM: Skin lipids and epidermal differentiation in atopic dermatitis. Clin Dermatol 2003;21:134-144.

30 Kim SR, Choi HS, Seo HS, Choi YK, Shin YC, Ko SG: Topical application of herbal mixture extract inhibits ovalbumin- or 2,4-dinitrochlorobenzene-induced atopic dermatitis. Evid Based Complement Alternat Med 2012; 2012:545497.

31 Modena BD, Dazy K, White AA: Emerging concepts: mast cell involvement in allergic diseases. Transl Res 2016;174:98-121.

32 Basketter DA, Gerberick GF, Kimber I: Skin sensitisation, vehicle effects and the local lymph node assay. Food Chem Toxicol 2001; 39:621-627.
33 Stahlmann R, Wegner M, Riecke K, Kruse M, Platzek T: Sensitising potential of four textile dyes and some of their metabolites in a modified local lymph node assay. Toxicology 2006; 219:113-123.

34 Danby SG, AlEnezi T, Sultan A, et al: Effect of olive and sunflower seed oil on the adult skin barrier: implications for neonatal skin care. Pediatr Dermatol 2013;30:42-50.

35 Shi J, Wang L, Lu Y, et al: Protective effects of seabuckthorn pulp and seed oils against radiation-induced acute intestinal injury. J Radiat Res 2017;58:24-32.

36 Souza CO, Teixeira AA, Biondo LA, Silveira LS, Calder P, Rosa Neto JC: Palmitoleic acid reduces the inflammation in LPS stimulated macrophages by inhibition of $N F \kappa B$, independently of PPARs. Clin Exp Pharmacol Physiol 2017;44:566-575.

37 Mishra KP, Chanda S, Karan D, Ganju L, Sawhney RC: Effect of seabuckthorn (Hippophae rhamnoides) flavone on immune system: an in vitro approach. Phytother Res 2008;22: 1490-1495.

38 Park JH, Kim MS, Jeong GS, Yoon J: Xanthii fructus extract inhibits TNF- $\alpha /$ IFN- $\gamma$ induced Th2-chemokines production via blockade of NF-kB, STAT1 and p38-MAPK activation in human epidermal keratinocytes. J Ethnopharmacol 2015;171:85-93.

39 Perros F, Hoogsteden HC, Coyle AJ, Lambrecht BN, Hammad H: Blockade of CCR4 in a humanized model of asthma reveals a critical role for DC-derived CCL17 and CCL22 in attracting Th2 cells and inducing airway inflammation. Allergy 2009;64:995-1002.

40 Nakazato J, Kishida M, Kuroiwa R, Fujiwara J, Shimoda M, Shinomiya N: Serum levels of Th2 chemokines, CCL17, CCL22, and CCL27, were the important markers of severity in infantile atopic dermatitis. Pediatr Allergy Immunol 2008; 19:605-613.

41 Qi XF, Kim DH, Yoon YS, et al: Bambusae caulis in Liquamen suppresses the expression of thymus and activation-regulated chemokine and macrophage-derived chemokine in human keratinocytes due to antioxidant effect. Evid Based Complement Alternat Med 2012;2012:617494.

42 Lejeune D, Dumoutier L, Constantinescu S, Kruijer W, Schuringa JJ, Renauld JC: Interleukin-22 (IL-22) activates the JAK/STAT, ERK, JNK, and p38 MAP kinase pathways in a rat hepatoma cell line. Pathways that are shared with and distinct from IL-10. J Biol Chem 2002;277:33676-33682.

43 Kwon DJ, Bae YS, Ju SM, et al: Casuarinin suppresses TARC/CCL17 and MDC/CCL22 production via blockade of NF- $\mathrm{kB}$ and STAT1 activation in $\mathrm{HaCaT}$ cells. Biochem Biophys Res Commun 2012;417:1254-1259. 